\title{
New Initiative: Neuropsychopharmacology Online Rapid Publication
}

We are pleased to announce a new initiative for scientists publishing in Neuropsychopharmacology: online rapid publication. Recognizing the rapid explosion in providing scientific information in a readily accessible electronic format, the American College of Neuropsychopharmacology (ACNP) has recently inaugurated a Scientific Website (http://www.acnp.org/sciweb/ default.html). A significant component of this website is dedicated to supplementing and enhancing publications in Neuropsychopharmacology. In particular, the ACNP Scientific Website now offers authors of manuscripts accepted by the journal the opportunity for rapid electronic publication prior to publication in the paper journal. The first phase of this project will be to publish accepted manuscripts immediately upon acceptance. A second phase that is planned in the months to come will involve the opportunity to have online discussions around individual papers. Selected commentaries may be selected for publication in the journal.

Authors of all manuscripts will be invited to publish their papers on the ACNP Scientific Website at the time of acceptance. Our goal is to have these manuscripts uploaded to the ACNP Scientific Website within 48 hours of acceptance by the editorial office. In order to use this new option, we simply request that authors provide their manuscript, tables, and figures on disk with their submissions to the editorial office. Additionally, authors will be asked to sign a transfer of copyright agreement when submitting manuscripts to the journal, the transfer becoming effective only upon acceptance.

At the time of acceptance, the editorial office will e-mail the electronic manuscript files to the ACNP webmaster in Nashville. Once the manuscript has been uploaded to the ACNP Scientific Website, the corresponding author and the editorial office will both receive an e-mail with a discrete URL for citation purposes, as well as a date of this electronic publication. In turn, the date of first electronic publication will be forwarded to Elsevier to be included as the date of publication in the paper version of the journal. While we hope that authors will avail themselves of this opportunity that will permit rapid dissemination of their data, this program is currently optional.

At a technical level, we are requesting that the electronic versions that are submitted with manuscripts be sent on a computer disk, in RTF format for text and in GIF or TIFF format for figures; we may, however, be able to convert other formats for inclusion on the website. Because of the low cost of server space, we are also planning to offer authors the opportunity to include supplemental material that would not be suitable for inclusion in the final print version of a manuscript. Files that would be appropriate for inclusion on the website include audio or video files, supplemental data and similar information. If authors are interested in any of these supplemental multimedia types of content, the editorial office should be alerted at the time of submission and the ACNP webmaster (webmaster@ACNP.org) can provide the technical specifications for submission of these materials.

In order to make this process as efficient and rapid as possible, manuscripts will be uploaded without proofreading or typesetting. Accordingly, authors will need to assume the responsibility for carefully proofreading their documents at the time submission, and are encouraged to inspect their work online once uploaded. The ACNP Scientific Website will also be linked through the Neuropsychopharmacology area directly to Elsevier's website (http://www.com/locate/nps), on which Neuropsychopharmacology is currently being published. In short, the ACNP is now offering the online presentation of an accepted paper within a very short 
period of time. Following the Elsevier copy editing and typesetting stage, these manuscripts will be uploaded in a parallel electronic format at the Elsevier website, where they will have the typeset appearance of what will appear in print. These two websites complement each other: The early ACNP online publication offers immediate dissemination of papers in addition to the opportunity for ongoing online dialogue around a given paper. The Elsevier site, on the other hand offers a formal format for manuscripts and powerful links through to journal archives and search engines like Medline. In addition, articles published in Neuropsychopharmacology are also located on Elsevier's Neuroscion server (http://neuroscion.com/). Neuroscion is a service that allows investigators to search across the entire catalog of Elsevier's neuroscience publications for information on specific topics: full text of these articles is available for a nominal fee.
We are pleased to be able to offer rapid online publication of accepted manuscripts for publication in $\mathrm{Neu}$ ropsychopharmacology. We anticipate this online format will provide new and creative opportunities not only for timely dissemination of data, but also a venue for interactive discussions among our scientific readership. In addition, we anticipate that this new phase in the evolution of the journal will bring a number of exciting changes for our readership in the months to come.

James H. Meador-Woodruff, M.D. Editor, ACNP Scientific Website

Robert H. Lenox, M.D. Editor-in-Chief, Neuropsychopharmacology 